\title{
Optimization of robusta green coffee fermentation using response surface methodology
}

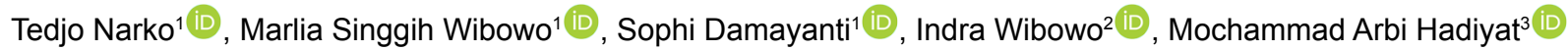

${ }^{1}$ Department of Pharmacochemistry, School of Pharmacy, Bandung Institute of Technology, Bandung, Indonesia.

${ }^{2}$ Department of Biology, School of Life Sciences and Technology, Bandung Institute of Technology, Bandung, Indonesia

${ }^{3}$ Department of Industrial Engineering, Surabaya University, Surabaya, Indonesia.

Contact authors: tedjo.n.83.128@gmail.com,marlia@fa.itb.ac.id, sophi.damayanti@gmail.com, bhowoind@gmail.com, arbi@staff.ubaya.ac.id

Received in November 11, 2019 and approved in July 29, 2020

\begin{abstract}
Kombucha coffee is a fermented coffee bean, which is extracted using a combination of bacteria and yeast. Kombucha coffee can be obtained by optimizing the three variables, namely sugar concentration, incubation temperature and duration of fermentation using a response surface methodology (RSM). This study aimed to produce kombucha coffee with a low concentration of caffeine and a high concentration of chlorogenic acid by optimizing three influential variables in the fermentation. The analysis of caffeine and chlorogenic acid contained in the kombucha coffee was carried out by using High Performance Liquid Chromatography (HPLC) and then the analysis of optimization was carried out by using Response Surface Methodology (RSM). The results of RSM show that the optimum condition was obtained at sugar concentration of $6.77 \%(\mathrm{~b} / \mathrm{v})$, incubation temperature of $25{ }^{\circ} \mathrm{C}$ and incubation for 18 days. The results were similar to HPLC analysis. Finally, the fermentation using RSM on kombucha coffee required an additional variable which is the amount of kombucha culture inoculums, as well as the variables of sugar concentration, incubation temperature, and duration of fermentation.
\end{abstract}

Key words: Kombucha coffee; caffeine; chlorogenic acid.

\section{INTRODUCTION}

Indonesia is the fourth largest coffee producer in the world after Brazil, Vietnam, and Colombia (Szenthe, 2019). A city in Indonesia that produces coffee is Garut, located in West Java. Two kinds of coffee that are commonly found in Indonesia are Arabica and Robusta coffee. Robusta coffee has a higher chemical content than Arabica coffee which contains 2.4-2.5 g/100 g of caffeine and 3.3-3.8 g/100g of chlorogenic acid (Farah, 2012). Coffee usually undergoes a roasting process to provide the coffee flavor. The roasting process can reduce the amount of chlorogenic acid that contributes to the final acidity, astringency, and bitterness of the coffee (Farah et al., 2006). Therefore, green coffee beans have a higher level of chlorogenic acid than ordinary coffee (roasted coffee beans).

Green coffee is coffee beans from the unroasted coffee fruit. Green coffee contains caffeine, trigonelline, carbohydrates, fats, amino acids, organic acids, phenolic minerals, and chlorogenic acid. The largest content in green coffee beans is caffeine and chlorogenic acid. Caffeine is a non-specific antagonist for adenosine receptors, which are widely distributed in the cortex (Ryan; Hatfield; Hofstetter, 2002; Chu, 2012). Caffeine works as a stimulant by blocking the adenosine receptors to inhibit the neurotransmitters (Ramachandran, 2002). Chlorogenic acid is the ester form of several cinnamic acids (cafeic acid, ferulic acid, and p-kumarat acid) with quinic acid available in a free form (Mursu et al., 2005). It is an antioxidant in the form of polyphenol compound that prevents cell mutation (Schieber; Saldana, 2009).
Several human clinical trials have been conducted to test the effectiveness and safety of chlorogenic acid in green coffee to reduce body weight and body mass in adults (Revuelta-Iniesta; Al-Dujaili, 2014; Cornelis, 2015). The optimum concentration of caffeine and chlorogenic acid can be employed by the addition of kombucha.

Kombucha is a fermented beverage that is produced from tea with the addition of kombucha culture (Jayabalan et al., 2008). This nutritious drink is widely consumed for therapeutic since thousands of years ago, especially in China and Korea. Kombucha is made from sweet tea and fermented with bacterial colonies and yeast. Kombucha is believed to be able to maintain the body by detoxifying, increasing stamina, improving the function of the small intestine, losing weight, and reducing cholesterol, acne, anxiety, arthritis, atherosclerosis, colitis, depression, diabetes, eczema, and tonsillitis (Childs; Childs, 2013). Kombucha is a symbiosis between bacteria and yeast, commonly called SCOBY. Acetobacter xylinum is a bacterium that is often found in the Kombucha culture, while some other species of yeast that have been isolated from Kombucha are Saccharomyces sp., Torulopsis famat, Pichia membranae, and Candida sp. Several factors may cause variation in the composition of kombuscha, including geographical condition, climate, culture, and the diversity of local species of bacteria and yeast (Teoh; Heard; Cox, 2004).

There are several parameters in fermentation that play an important role in to succeed in the bioprocess industry besides the microorganism used, such as the increasing of inoculum 
concentration, urea concentration, and fermentation time. Several studies have investigated the effect of the addition of Zymomonas mobilis inoculums, urea concentrations in various fermentation mediums and the duration of fermentation were carried out (Nofemele et al., 2012). Meanwhile, there is a method that can be developed to optimize the fermentation process, called RSM (Ambati; Ayyanna, 2001; Lotfy; Ghanem; Elhelow, 2007).

RSM is a combination of mathematical and statistical techniques used for modeling and analyzing problems in a form of response influenced by several variables. The goal is to optimize the reaction by optimizing the variable levels to achieve the best systematic performance. This method can be used for research with a large number of factors with three and five levels of treatment. The use of this RSM can display a 3-dimensional graph using statistical software. RSM can be used to determine the optimal point of multifactor experiments (Myers; Montgomery; Anderson-Cook, 2009).

Regarding modeling, RSM uses the basis of mathematical equations that are developed at an experimental level so that the relationship with experimental data can only be analyzed through statistical models. The advantage of using RSM is to determine the optimum results where there is a need to shift the level of factors studied in the direction of an optimal response. The process is referred to as the steepest ascent/descent (Myers; Montgomery; Anderson-Cook, 2009). The RSM method was chosen because it's able to explore the correlation between many factors to get the most optimal conditions for production in a bioprocess and to predict the response (Chang; Lee; Pan, 2006)

In this study, RSM was used to optimize the fermentation of Robusta green coffee beans through kombucha culture. There are three variables in the fermentation of kombucha coffee which will be examined including the concentration of sugar, incubation temperature, and duration of fermentation.

\section{MATERIAL AND METHODS}

For the current research, the materials used were Robusta green coffee beans from Garut, West Java, Indonesia (Determination of plants by SITH ITB No. 2833/I1.CO2.2./ PL/2017), starter kombucha (Indokombucha), sugar, methanol, acetic acid and distilled water (Merck). The analysis of caffeine and chlorogenic acid used a membrane filter of $0.45 \mu \mathrm{m}$. The instruments used were: high-performance liquid chromatography (HPLC) C-18 with a column length of $150 \mathrm{~mm}$ and a diameter of $4.6 \mathrm{~mm}$ and UV detector, and the Minitab software v.17.

\subsection{Preparation of coffee}

The Robusta coffee bean was processed first before the fermentation process carried out. After harvested, $2 \mathrm{~kg}$ of coffee bean was experienced a wet process by putting it into pulper machine to remove the skin. Then it was soaked for several days and washed. It was dried in the sun or by using a dryer. It was placed into huller machine or pounded to remove the horn skin and then sorted.

\subsection{Fermentation process}

The fermentation process of kombucha coffee followed the research conducted by Jayabalan et. al (2008) with modification. It used Acetobacter xylinum and Saccharomyces cerevisiae which included several steps. About $0.375 \mathrm{~g}$ of simplicia powder (the beans which have been dried and ground) of Robusta green coffee was added into $300 \mathrm{~mL}$ distilled water. It was added with sugar in various concentrations of $5 ; 7.5$; and $10 \%(\% \mathrm{w} / \mathrm{v})$ and stirred. The mixture was cooled and filtered. The filtrate was added with $30 \mathrm{~mL}$ kombucha vinegar (the ratio of filtrate and vinegar was 10:1). The mixture was homogenized and placed into a sterile glass jar. About $20 \mathrm{~g}\left(10^{8}\right.$ $\mathrm{CFU} / \mathrm{mL}$ ) starter kombucha (purchased from Indokombucha) was inoculated into each jar. The jar was covered with sterile porous cloth and stored in the incubator. It should be not to shake or move. The temperature was also varied of 25,31 , and $37^{\circ} \mathrm{C}$ and the incubation time was varied of $6,12,18$ hours.

The harvest time of the products was carried out due to the incubation time of each sample. The vinegar of kombucha coffee was separated from the culture of kombucha which was formed on the surface. The vinegar then centrifuged with 6000 rpm for $40 \mathrm{~min}$ to precipitate the culture fibers. The filtrate then placed into the sterile glass bottle and tightly closed.

\subsection{Quantitative analysis of caffeine and chlorogenic acid}

Ten $\mathrm{mL}$ of samples of kombucha coffee was filtered using a $0.45 \mu \mathrm{M}$ membrane filter. As much as $20 \mu \mathrm{L}$ of the samples were analyzed by HPLC using a C-18 column. As for the caffeine analysis, the mobile phase used was methanol:water (7:3) with a flow rate of $1.0 \mathrm{~mL} /$ minute using a UV detector at $\lambda=273 \mathrm{~nm}$. The mobile phase used for chlorogenic acid content was methanol:double-distilled water with $1 \%$ acetic acid (40:60), a flow rate of $1.0 \mathrm{~mL} /$ minute using a UV detector at $\lambda=329 \mathrm{~nm}$.

\subsection{RSM modeling using Minitab}

This study used a central composite experimental design (CCD) to find the optimum combination of sugar concentration, incubation temperature, and fermentation time to produce the optimum caffeine and chlorogenic acid. Data obtained was based on a statistical design which analyzed by using the Minitab v.17 program and an analysis of variance (ANOVA) to test the significance. Three-dimensional curves were used to test the validity of the variable's effect on the results obtained. The coefficients on the empirical model were 
estimated using a multi-directional regression analysis, where the fitness of the empirical model with experimental data could be determined from the coefficient of determination (R2). Regression equations obtained after regression analysis were used to find the most optimal response conditions. In general, the general RSM regression Equation 1 was:

$Y=\beta_{0}+\beta_{1} X_{1}+\beta_{2} X_{2}+\beta_{3} X_{3}+\beta_{4} X_{1}^{2}+\beta_{5} X_{2}^{2}+$

$+\beta_{6} X_{3}^{2}+\beta_{7} X_{1} X_{2}+\beta_{8} X_{1} X_{3}+\beta_{9} X_{2} X_{3}$

Where $\mathrm{Y}=$ estimated results, $\beta_{0}=$ intercept coefficient, $\beta_{I} X_{1}+$ $\beta_{2} X_{2}+\beta_{3} X_{3}=$ linear component, $\beta_{4} X_{1}^{2}+\beta_{5} X_{2}^{2}+\beta_{6} X_{3}^{2}=$ quadratic component, $\beta_{7} X_{1} X_{2}+\beta_{8} X_{1} X_{3}+\beta_{9} X_{2} X_{3}=$ interaction component, while the independent variables were sugar concentration $\left(\mathrm{X}_{1}\right)$, temperature incubation $\left(\mathrm{X}_{2}\right)$ and fermentation time $\left(\mathrm{X}_{3}\right)$. The coded value of this study can be seen in Table 1 . Table 1 shows the coded values of the three parameters used in this study. The lowest coded value was -1 , the middle value was 0 , and the highest value was 1 . The results of the RSM modeling using the central composite experimental design (CCD) can be seen in Table 2 .

Table 1: The codification of the research variables.

\begin{tabular}{cccccccc}
\hline \multirow{2}{*}{ Factors } & \multicolumn{3}{c}{ Original value } & \multicolumn{3}{c}{ Coded values } \\
\cline { 2 - 7 } & Low & mid & high & low & mid & high \\
\hline Sugar concentration $(\% \mathrm{w} / \mathrm{v})$ & 5 & 7.5 & 10 & -1 & 0 & 1 \\
Incubation temperature $\left({ }^{\circ} \mathrm{C}\right)$ & 25 & 31 & 37 & -1 & 0 & 1 \\
Fermentation time (days) & 6 & 12 & 18 & -1 & 0 & 1 \\
\hline
\end{tabular}

Table 2: The number of samples obtained from RSM by using a program of Minitab v.17.

\begin{tabular}{cccc}
\hline No. & $\begin{array}{c}\text { Sugar } \\
\text { concentration } \\
(\% \mathrm{w} / \mathrm{v})\end{array}$ & $\begin{array}{c}\text { Incubation } \\
\text { temperature } \\
\left({ }^{\circ} \mathrm{C}\right)\end{array}$ & $\begin{array}{c}\text { Fermentation time } \\
(\text { days })\end{array}$ \\
\hline 1 & 1 & 1 & 1 \\
2 & -1 & -1 & -1 \\
3 & 1 & -1 & -1 \\
4 & 1 & 1 & -1 \\
5 & -1 & -1 & 1 \\
6 & 0 & 0 & 0 \\
7 & 1 & -1 & 1 \\
8 & -1 & 1 & 1 \\
9 & 0 & 0 & 0 \\
10 & 0 & 0 & 0 \\
11 & 0 & 0 & 0 \\
12 & 0 & 0 & 0 \\
13 & -1 & 1 & -1 \\
14 & 0 & 0 & 0 \\
\hline
\end{tabular}

Based on the results of data processing with CCD, an optimal point will be searched through experiments involving several factors. The experiment was designed to get the response area which included three optimal points of three variables: sugar concentration, incubation temperature, and incubation time. Thus, the optimal point obtained is not a "local optimum" but can reach or at least approach the "global optimum" position of the response variable. Based on the data in Table 2, the results of RSM data processing were obtained using three research variables, the sugar concentration, incubation temperature and fermentation time which resulted in 14 sample combinations of three variables. These 14 combination samples will be tested to obtain the optimum results on caffeine and chlorogenic acid content of fermented Robusta green coffee beans using a kombucha culture.

\section{RESULTS AND DISCUSSION}

\subsection{Caffeine and chlorogenic acid analysis}

Based on the data in Table 3, the results showed that the lowest caffeine content was $21.98 \mathrm{mg} / \mathrm{L}$ obtained at a condition of $7.5 \%$ sugar concentration, an incubation temperature of $31^{\circ} \mathrm{C}$, and a fermentation time of 12 days. While the highest caffeine concentration was $29.34 \mathrm{mg} / \mathrm{L}$ obtained at a condition of $10 \%$ sugar concentration, an incubation temperature of $25{ }^{\circ} \mathrm{C}$, and a fermentation time of 6 days. Table 4 shows that the lowest chlorogenic acid level was $105.15 \mathrm{mg} / \mathrm{L}$ obtained at a condition of $10 \%$ sugar concentration, an incubation temperature of $25^{\circ} \mathrm{C}$, and an incubation time of 6 days. While the highest chlorogenic acid concentration was $144.37 \mathrm{mg} / \mathrm{L}$ which was obtained at a condition of sugar concentration of $5 \%$, an incubation temperature of $25^{\circ} \mathrm{C}$, and an incubation time of 18 days.

\subsection{Processing data using RSM}

The estimated regression coefficient of caffeine and chlorogenic acid was obtained by using Minitab v.17 which can be seen in Table 4 and Table 5. Based on the results of RSM analysis for Caffeine (Equation 2) and Chlorogenic acid (Equation 3), an equation was obtained:

$$
\begin{aligned}
& y=22.4217-0.035 X_{1}+0.6675 X_{2}-0.9525 X_{3}+ \\
& +5.8 X_{1}^{2}+0.765 X_{2} X_{3} \\
& y=121.803-4.301 X_{1}-4.816 X_{2}+10.541 X_{3}+4.649 X_{1} X_{2}
\end{aligned}
$$

Based on the data in Table 4 and 5, the results of the coefficient of determination, $\mathrm{R}^{2}$ for caffeine was $98.93 \%$ and $\mathrm{R}^{2}=95.53 \%$ for chlorogenic acid. From this value, it can be concluded that the value estimated using the model approaches the value obtained from the experimental results. This result 
shows that the value of $\mathrm{R}^{2}=98.93 \%$ for caffeine and $\mathrm{R}^{2}=$ $95.53 \%$ for chlorogenic acid from the total value of variation is represented by the results of the test.

A comparison table of the results of the analysis of caffeine and chlorogenic acid content using HPLC compared with the results of calculations using the RSM equation can be seen in Tables 6 and 7 .
The data in Tables 6 and 7 revealed that the comparison of the caffeine analysis using HPLC or RSM equation shows a percentage ranging from $0.17 \%-3.19 \%$, while the chlorogenic acid test results obtained ranged from $0.32 \%-2.99 \%$. These results indicate that the two methods give similar results of caffeine and chlorogenic acid content.

Table 3: Caffeine and chlorogenic acid content from Robusta green coffee fermentation using a kombucha culture by using HPLC on 14 combination samples obtained from the study design using Minitab v.17.

\begin{tabular}{cccccc}
\hline No. & $\begin{array}{c}\text { Sugar concentration } \\
(\% \mathrm{w} / \mathrm{v})\end{array}$ & $\begin{array}{c}\text { Incubation temperature } \\
\left({ }^{\circ} \mathrm{C}\right)\end{array}$ & $\begin{array}{c}\text { Fermentation time } \\
(\text { days })\end{array}$ & $\begin{array}{c}\text { Caffeine concentration } \\
(\mathrm{mg} / \mathrm{L})\end{array}$ & $\begin{array}{c}\text { Chlorogenic } \\
\text { acid concentration }(\mathrm{mg} / \mathrm{L})\end{array}$ \\
\hline 1 & 1 & 1 & 1 & $28.72 \pm 3.17$ & $127.47 \pm 1.15$ \\
2 & -1 & -1 & -1 & $29.21 \pm 1.44$ & $128.75 \pm 1.47$ \\
3 & 1 & -1 & -1 & $29.34 \pm 0.35$ & $105.15 \pm 0.61$ \\
4 & 1 & 1 & -1 & $29.12 \pm 1.23$ & $109.18 \pm 2.01$ \\
5 & -1 & -1 & 1 & $26.10 \pm 1.52$ & $144.37 \pm 1.08$ \\
6 & 0 & 0 & 0 & $22.10 \pm 1.51$ & $119.47 \pm 1.02$ \\
7 & 1 & -1 & 1 & $25.58 \pm 0.76$ & $132.17 \pm 1.09$ \\
8 & -1 & 1 & 1 & $28.69 \pm 2.28$ & $129.33 \pm 1.67$ \\
9 & 0 & 0 & 0 & $23.16 \pm 2.67$ & $119.98 \pm 2.68$ \\
10 & 0 & 0 & 0 & $22.12 \pm 3.49$ & $120.45 \pm 3.61$ \\
11 & 0 & 0 & 0 & $22.97 \pm 2.23$ & $121.02 \pm 2.22$ \\
12 & 0 & 0 & 0 & $21.98 \pm 0.91$ & $119.29 \pm 2.41$ \\
13 & -1 & 1 & -1 & $29.04 \pm 3.05$ & $105.93 \pm 0.29$ \\
14 & 0 & 0 & 0 & $22.20 \pm 1.63$ & $122.68 \pm 0.95$ \\
\hline
\end{tabular}

Table 4: Estimated regression coefficients for caffeine.

\begin{tabular}{ccccc}
\hline Term & Coef & SE Coef & T & P \\
\hline Constant & 22.4217 & 0.1721 & 130.269 & 0.000 \\
X1-Sugar & -0.0350 & 0.1491 & -0.235 & 0.820 \\
X2-Temperature & 0.6675 & 0.1491 & 4.478 & 0.002 \\
X3-Time & -0.9525 & 0.1491 & -6.390 & 0.000 \\
X1-Sugar*X1-Sugar & 5.8033 & 0.2277 & 25.488 & 0.000 \\
X2-Temp*X3-Time & 0.7650 & 0.1491 & 5.132 & 0.001 \\
& & $\mathrm{~S}=0.421602$ PRESS $=2.82743 \quad$ & \\
\end{tabular}

Table 5: Estimated regression coefficients for chlorogenic acid.

\begin{tabular}{ccccc}
\hline Term & Coef & SE Coef & T & P \\
\hline Constant & 121.803 & 0.7198 & 169.223 & 0.000 \\
X1-Sugar & -4.301 & 0.9522 & -4.517 & 0.001 \\
X2-Temperature & -4.816 & 0.9522 & -5.058 & 0.001 \\
X3-Time & 10.541 & 0.9522 & 11.071 & 0.000 \\
X1-Sugar*X2-Temp & 4.649 & 0.9522 & 4.882 & 0.001 \\
\hline & $\mathrm{R}-\mathrm{Sq}=95.53 \%$ R-Sq(pred) $=81.03 \%$ R-Sq(adj) $=93.54 \%$ \\
\hline
\end{tabular}


Table 6: Comparison of caffeine content based on HPLC analysis with RSM calculations.

\begin{tabular}{cccc}
\hline No. & $\begin{array}{c}\text { Concentration } \\
(\mathrm{mg} / \mathrm{L}) \text { HPLC }\end{array}$ & $\begin{array}{c}\text { Concentration } \\
(\mathrm{mg} / \mathrm{L}) \\
\mathrm{RSM}\end{array}$ & $\begin{array}{c}\text { Percentage of } \\
\text { ratio } \\
(\%)\end{array}$ \\
\hline 1 & $28.72 \pm 3.17$ & 28.67 & 0.17 \\
2 & $29.21 \pm 1.44$ & 29.31 & 0.34 \\
3 & $29.34 \pm 0.35$ & 29.24 & 0.34 \\
4 & $29.12 \pm 1.23$ & 29.04 & 0.28 \\
5 & $26.10 \pm 1.52$ & 25.87 & 0.88 \\
6 & $22.10 \pm 1.51$ & 22.42 & 1.43 \\
7 & $25.58 \pm 0.76$ & 25.80 & 0.85 \\
8 & $28.69 \pm 2.28$ & 28.74 & 0.17 \\
9 & $23.16 \pm 2.67$ & 22.42 & 3.19 \\
10 & $22.12 \pm 3.49$ & 22.42 & 1.34 \\
11 & $22.97 \pm 2.23$ & 22.42 & 2.39 \\
12 & $21.98 \pm 0.91$ & 22.42 & 1.96 \\
13 & $29.04 \pm 3.05$ & 29.11 & 0.24 \\
14 & $22.20 \pm 1.63$ & 22.42 & 0.98 \\
\hline
\end{tabular}

Table 7: Comparison of chlorogenic acid content based on HPLC analysis with RSM calculations.

\begin{tabular}{cccc}
\hline No. & $\begin{array}{c}\text { Concentration } \\
(\mathrm{mg} / \mathrm{L}) \text { HPLC }\end{array}$ & $\begin{array}{c}\text { Concentration } \\
(\mathrm{mg} / \mathrm{L}) \\
\mathrm{RSM}\end{array}$ & $\begin{array}{c}\text { Percentage of } \\
\text { ratio } \\
(\%)\end{array}$ \\
\hline 1 & $127.47 \pm 1.15$ & 127.88 & 0.32 \\
2 & $128.75 \pm 1.47$ & 125.03 & 2.89 \\
3 & $105.15 \pm 0.61$ & 107.13 & 1.85 \\
4 & $109.18 \pm 2.01$ & 106.80 & 2.18 \\
5 & $144.37 \pm 1.08$ & 146.11 & 1.19 \\
6 & $119.47 \pm 1.02$ & 121.80 & 1.91 \\
7 & $132.17 \pm 1.09$ & 128.21 & 2.99 \\
8 & $129.33 \pm 1.67$ & 127.18 & 1.66 \\
9 & $119.98 \pm 2.68$ & 121.80 & 1.49 \\
10 & $120.45 \pm 3.61$ & 121.80 & 1.11 \\
11 & $121.02 \pm 2.22$ & 121.80 & 0.64 \\
12 & $119.29 \pm 2.41$ & 121.80 & 2.06 \\
13 & $105.93 \pm 0.29$ & 106.10 & 0.16 \\
14 & $122.68 \pm 0.95$ & 121.80 & 0.71 \\
\hline
\end{tabular}

\subsection{ANOVA test}

According to the ANOVA test result in Tables 8 and 9 , the $\mathrm{P}$ regression value of caffeine and chlorogenic acid was 0.000 , indicating that the three variables, sugar concentration, incubation temperature and incubation time have significant $(\mathrm{P}<0.01)$ affect the caffeine and chlorogenic acid concentrations.

\subsection{Optimization of the fermentation of kombucha coffee}

The results of the optimization test for fermentation of caffeine and chlorogenic acid content using 3 parameters, sugar concentration, incubation temperature and incubation time can be seen in Figure 1 and Figure 2. Figure 1 shows a caffeine content which is influenced by the sugar concentration and incubation time. It can be seen from the results of the surface plots that indicate the presence of optimum points. The chlorogenic acid didn't show an optimum point from the calculation of RSM (Figure 2).

\subsection{The study of RSM method}

The calculations of RSM can be concluded in Table 10. The optimum results of caffeine and chlorogenic acid levels from green coffee kombucha with three conditions, sugar concentration, incubation temperature and fermentation time showed the highest results at $6.77 \%$ sugar concentration, an incubation temperature of $25{ }^{\circ} \mathrm{C}$ and an incubation time of 18 days. The caffeine content reached $20.56 \mathrm{mg} / \mathrm{L}$, while the chlorogenic acid content was $138.78 \mathrm{mg} / \mathrm{L}$.

Kombucha is commonly used in the traditional fermentation of tea by adding sugar and kombucha so it produces a slightly sour taste to a strong acid depending on the amount of sugar used, fermentation time and temperature (Lee, 2014). The kombucha culture can grow at temperatures of $20-50{ }^{\circ} \mathrm{C}$ with a different growing speed (El-Salam, 2012). Meanwhile, sugar addition was used as the carbon source for kombucha to grow. The concentration of $10 \% \mathrm{w} / \mathrm{v}$ was chosen as the highest concentration due to the research conducted by El-Salam (2012) which concluded that the sucrose addition of $10 \% \mathrm{w} / \mathrm{v}$ resulted in the thickest nata. The yeast which is used in a medium with high glucose will synthesize glucose about $3-20 \%$ meanwhile the excess glucose will be used in the fermentation process (Moat; Foster; Spector, 2002). In the present study, kombucha vinegar was also added to provide the first nutrition for the bacteria because it contains glucose and alcohol. Along with the fermentation occurred, there was a symbiosis between bacteria (Acetobacter xylinum) and aerobic yeast (Saccharomyces cerevisiae). Due to the yeast, the porous cloth was used to keep the air circulation. During the fermentation, the jar should be not to shake or move because it can affect the culture growth where the cellulose fibers cannot be a good array.

The optimization resulted in an increase in the concentration of chlorogenic acid by increasing the incubation time. But, it cannot be concluded when the formation of chlorogenic acid stops because the maximum incubation time used in this study was only 18 days. The results show that the RSM analysis did not show a significant difference compared with HPLC. The percentage has a similar value, about 0.1- 
$3.19 \%$ for caffeine and $0.32-2.99 \%$ for chlorogenic acid. The optimum sugar concentration from fermented Robusta green coffee beans using a kombucha culture was $6.77 \%$. During the fermentation process Acetobacter xylinum breaks down sucrose into glucose and fructose (Chen; Liu, 2000), then it is continuously transformed into organic acids and alcohol until the sugar runs out, the acidity will also increase during the fermentation process. In the fermentation process, the sugar is used as a source of nutrients and will be converted into alcohol and $\mathrm{CO}_{2} \cdot \mathrm{CO}_{2}$ gas will react with water vapor and form carbonic acid which can provide carbonation effects on alcoholic beverages, as well as in kombucha drinks. According to Kim and Gadd (2008), the Acetobacter xylinum is an over-oxidizer which can convert acetic acid into $\mathrm{CO}_{2}$ and $\mathrm{H}_{2} \mathrm{O}$ gas. Acetic acid is used by Acetobacter xylinum as a substrate to generate the optimum conditions for its growth and to form $\mathrm{CO}_{2}$ and $\mathrm{H}_{2} \mathrm{O}$ gases. In contrast, the caffeine reduction in the fermentation of kombucha coffee was caused by the kombucha culture which oxidized the atom of carbon in the position of C-8. The enzyme of caffeine oxidase played a role in the first degradation which produced 1,3,7-trimethylouric acid. The presence of bacteria would reduce the caffeine concentration with the main route of theobromine to 7-methylxanthine then into xanthine (Mazzafera, 2004).

The optimum incubation temperature calculated using RSM was $25^{\circ} \mathrm{C}$. It shows that temperature plays a significant role in determining the fermentation rate and the composition of the final fermentation product. Kombucha requires an optimal temperature range between $23-29{ }^{\circ} \mathrm{C}$. In this study, the incubation temperature was $31^{\circ} \mathrm{C}$. It was intended to determine the extent of yeast growth in SCOBY which generally grows and develops in a temperature range of $25-30{ }^{\circ} \mathrm{C}$. According to Sibirny (2017), the optimal

Table 8: Analysis of variance for caffeine.

\begin{tabular}{|c|c|c|c|c|c|c|}
\hline Source & $\mathrm{DF}$ & Seq SS & Adj SS & Adj MS & $\mathrm{F}$ & $\mathrm{P}$ \\
\hline Regression & 5 & 130.984 & 130.984 & 26.197 & 147.38 & 0.000 \\
\hline Linear & 3 & 10.832 & 10.832 & 3.611 & 20.31 & 0.000 \\
\hline X1-Sugar & 1 & 0.010 & 0.010 & 0.010 & 0.06 & 0.820 \\
\hline $\mathrm{X} 2$-Temperature & 1 & 3.564 & 3.564 & 3.564 & 20.05 & 0.002 \\
\hline X3-Time & 1 & 7.258 & 7.258 & 7.258 & 40.83 & 0.000 \\
\hline Square & 1 & 115.470 & 115.470 & 115.470 & 649.63 & 0.000 \\
\hline X1-Sugar*X1-Sugar & 1 & 115.470 & 115.470 & 115.470 & 649.63 & 0.000 \\
\hline Interaction & 1 & 4.682 & 4.682 & 4.682 & 26.34 & 0.001 \\
\hline X2-Temp*X3-Time & 1 & 4.682 & 4.682 & 4.682 & 26.34 & 0.001 \\
\hline Residual Error & 8 & 1.422 & 1.422 & 0.178 & & \\
\hline Lack-of-Fit & 3 & 0.138 & 0.138 & 0.046 & 0.18 & 0.907 \\
\hline Pure Error & 5 & 1.284 & 1.284 & 0.257 & & \\
\hline Total & 13 & 132.406 & & & & \\
\hline
\end{tabular}

Table 9: Analysis of variance for chlorogenic acid.

\begin{tabular}{|c|c|c|c|c|c|c|}
\hline Source & DF & Seq SS & Adj SS & Adj MS & $\mathrm{F}$ & $\mathrm{P}$ \\
\hline Regression & 4 & 1395.41 & 1395.41 & 348.852 & 48.10 & 0.000 \\
\hline Linear & 3 & 1222.52 & 1222.52 & 407.507 & 56.18 & 0.000 \\
\hline X1-Sugar & 1 & 148.01 & 148.01 & 148.006 & 20.41 & 0.001 \\
\hline $\mathrm{X} 2$-Temperature & 1 & 185.57 & 185.57 & 185.570 & 25.59 & 0.001 \\
\hline X3-Time & 1 & 888.94 & 888.94 & 888.944 & 122.56 & 0.000 \\
\hline Interaction & 1 & 172.89 & 172.89 & 172.887 & 23.84 & 0.001 \\
\hline X1-Sugar*X3-Temp & 1 & 172.89 & 172.89 & 172.887 & 23.84 & 0.001 \\
\hline Residual Error & 9 & 65.28 & 65.28 & 7.253 & & \\
\hline Lack-of-Fit & 4 & 57.46 & 57.46 & 14.365 & 9.19 & 0.016 \\
\hline Pure Error & 5 & 7.82 & 7.82 & 1.564 & & \\
\hline Total & 13 & 1460.68 & & & & \\
\hline
\end{tabular}


temperature for ethanol fermentation is $25-35{ }^{\circ} \mathrm{C}$. While the temperature at $37{ }^{\circ} \mathrm{C}$ was intended to determine the growth rate of bacteria which generally grows optimally at an incubation temperature of $37{ }^{\circ} \mathrm{C}$. The kombucha fermentation process must produce an optimal $\mathrm{pH}$ between 2.5-3.5 (Naland, 2004). The low pH of kombucha can prevent other bacteria to grow because the environment is not optimal for survival or reproduction. This condition lead the desired bacteria for fermentation grow properly (May et al., 2019). Thus the appropriate incubation temperature will support the growth of kombucha colonies and increase the quality of the kombucha products produced.

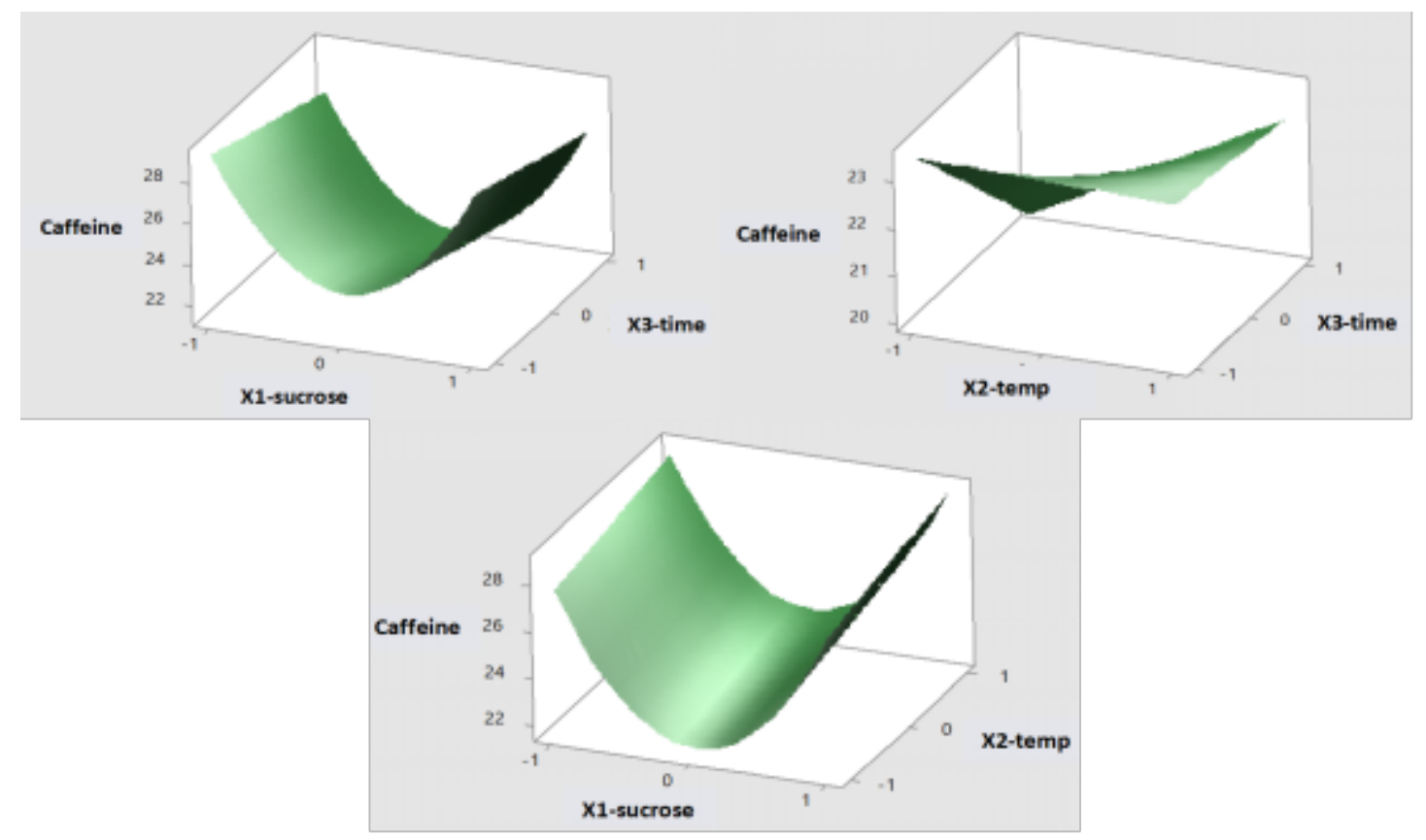

Figure 1: Response surface plot of caffeine content from sugar concentration, incubation temperature and incubation time based on the central composite experimental design results.

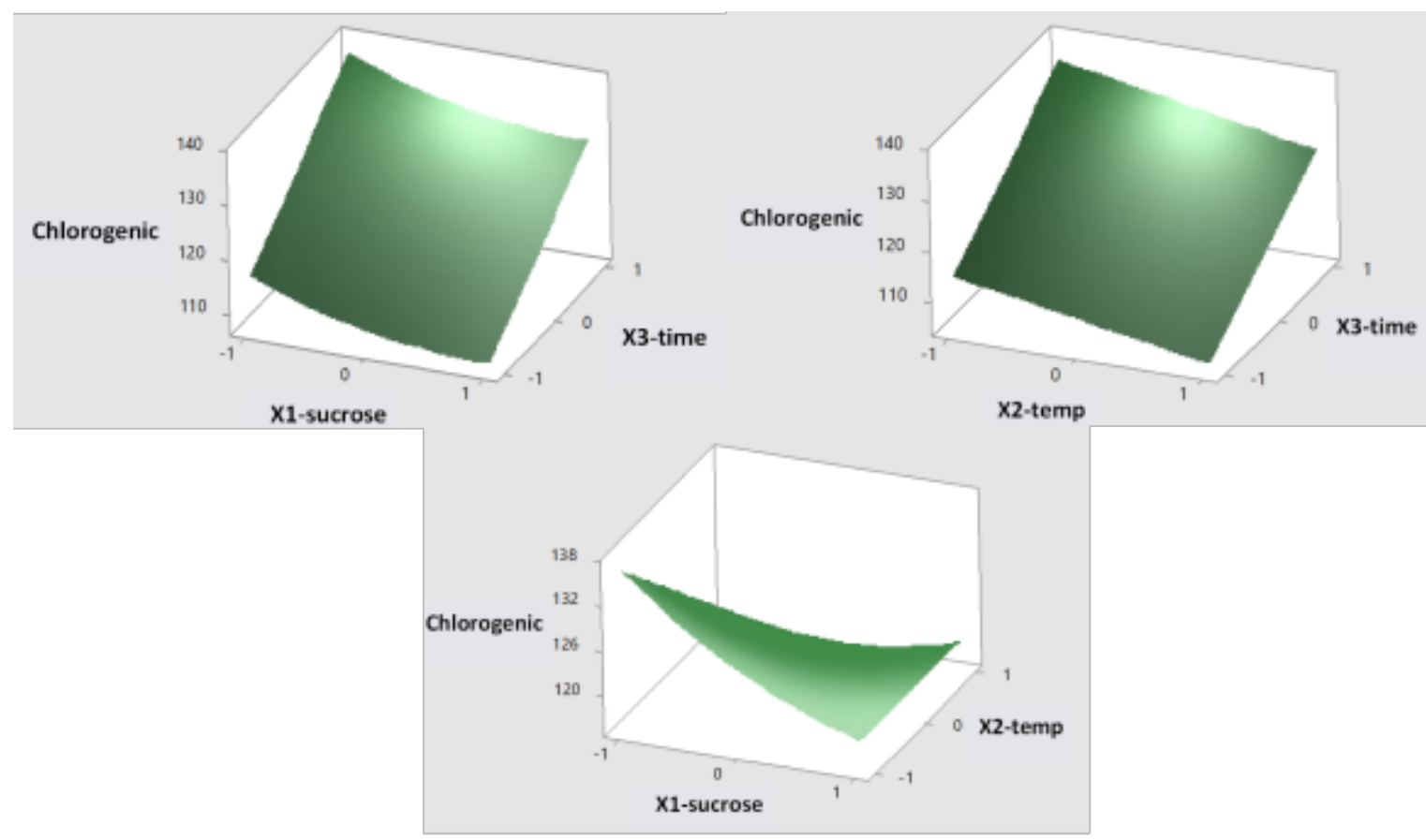

Figure 2: Response surface plot of chlorogenic acid content from sugar concentration, incubation temperature and incubation time variables based on the results of the central composite experimental design. 
Table 10: Results of optimization using the RSM method.

\begin{tabular}{ccccc}
\hline $\begin{array}{c}\text { Optimum Sugar } \\
\text { Concentration }\left(\mathrm{X}_{1}\right)\end{array}$ & $\begin{array}{c}\text { Optimum Incubation } \\
\text { Temperature }\left(\mathrm{X}_{2}\right)\end{array}$ & $\begin{array}{c}\text { Optimum Incubation } \\
\text { Time }\left(\mathrm{X}_{3}\right)\end{array}$ & $\begin{array}{c}\text { Estimated Caffeine } \\
\text { Concentration }\end{array}$ & $\begin{array}{c}\text { Estimated Chlorogenic } \\
\text { acid Concentration }\end{array}$ \\
\hline 6.77 & 25 & 18 & 20.56 & 138.78 \\
\hline
\end{tabular}

The optimum incubation time obtained from the RSM calculation was 18 days. This study revealed that the kombucha fermentation process was longer than the theoretical incubation period required, which is $8-14$ days. This condition was supposedly due to the phase lag (adaptation) shift, where the theoretical incubation of 8-14 days was obtained by using the fermentation medium of tea shifted to 18 days by using a fermentation medium of green coffee.

During the fermentation process, the formation of new kombucha cultures will continue until it becomes ideal and obtain the optimum concentration of caffeine and chlorogenic acid. The kombucha fermentation process is influenced by several environmental factors such as the amount of inoculum, incubation temperature, $\mathrm{pH}$ and initial sucrose levels (Mueller, 2014).

\section{CONCLUSIONS}

The analysis by using RSM did not give a significant difference compared to HPLC. The percentage was similar, about $0.17-3.19 \%$ for caffeine and $0.32-2.99 \%$ for chlorogenic acid. The optimum condition was obtained when the concentration of sugar was $6.77 \%$, incubation temperature was $25^{\circ} \mathrm{C}$, and the incubation time was 18 days. Therefore, $\mathrm{RSM}$ can be developed as a reference to optimize the other parameters to increase the quality of fermented samples.

\section{REFERENCES}

AMBATI, P.; AYYANNA, C. Optimizing medium constituents and fermentation condition for citric acid production from palmyra jaggery using responds surface method. World Journal of Microbiology and Biotechnology, 17(4):331-335, 2001.

CHANG, Y. C.; LEE, C. L.; PAN, T. M. Statistical optimization of media components for the production of Antrodia Cinnamomea AC0623 in submerged cultures. Applied Microbiology and Biotechnology, 72(4):654661, 2006.

CHEN, C.; LIU, B. Y. Changes in major components of tea fungus metabolites during prolonged fermentation. Journal of Applied Microbiology, 89(5):834-839, 2000 .

CHILDS, E.; CHILDS, J. Kombucha! The amazing probiotic tea that cleanses, heals, energizes, and detoxifies. New York: Penguin Random House Company, p.67-89, 2013.

CHU, Y. F. Coffee: Emerging health effects and disease prevention. Iowa, Wiley-Blackwell, West Sussex and Oxford, 2012. 352p.

CORNELIS, M. C. Toward systems Epidemiology of Coffee and Health. Current Opinion in Lipidology, 26(1):20$29,2015$.

EL-SALAM, S. S. A. Bacterial cellulose of kombucha mushroom tea. New York Science Journal, 5(4):81-87, 2012.

FARAH, A. Coffee Constituents. In: CHU, Y. F. Coffee: Emerging health effects and disease prevention. 1st ed. USA: Blackwell Publishing Ltd., p.21-50, 2012.

FARAH, A. et al. Chlorogenic Acids And Lactones In Regular And Water-Decaffeinated Arabica Coffee. Journal of Agricultural and Food Chemistry, 54(2):374-381, 2006.

JAYABALAN, R. et al. Changes in free-radical scavenging ability of kombucha tea during fermentation. Food Chemistry, 109(1):227-234, 2008.

KIM, B. H.; GADD, G. M. Bacterial physiology and metabolism. USA: Cambridge University Press, p.78-90, 2008.

LEE, S. Kombucha revolution: 75 recipes for homemade brews, fixers, elixirs, and mixers. United States: Ten Speed Press, p.56-67, 2014.

LOTFY, W. A.; GHANEM, K. M.; ELHELOW, E. R. Citric acid production by novel Aspergillus niger isolate: II. optimization of process parameter through statistical experiment designs. Bioresource Technology, 98(18):3470-3477, 2007.

MAY, A. et al. Kombucha: A novel model system for cooperation and conflict in a complex multi-species microbial ecosystem. PeerJ, 7:e7565. 2019.

MAZZAFERA, P. Catabolism of caffeine in plants and microorganisms. Frontiers in Biosciences, 1(9):1348-59, 2004.

MOAT, A. G.; FOSTER, J. W.; SPECTOR, M. P. Microbial Physiology. New York: Wiley-Liss, Inc. 2002. 734p. 
MUELLER, J. Delicious probiotics drinks: 75 recipes for kombucha, kefir, ginger beer, and other naturally fermented drinks. New York: Skyhorse Publishing, p.4578, 2014.

MURSU, J. et al. The effects of coffee consumption on lipid peroxidation and plasma total homocysteine concentrations a clinical trial. Free Radical Biology and Medicine, 38(4):527-534, 2005.

MYERS, R. H.; MONTGOMERY, D. C.; ANDERSONCOOK, C. M. Response surface methodology: Process and optimization using designed experiment. New York: John Wiley \& Sons, p.34-56, 2009.

NALAND, H. Kombucha: Teh ajaib pencegah dan penyembuh aneka penyakit. Indonesian: AgroMedia Pustaka, Jakarta. 2004. 56p.

NOFEMELE, Z. et al. Improvement of ethanol production from sugarcane molasses through enhanced nutrient supplementation using saccharomyces cerevisiae. Journal of Brewing and Distilling, 3(2):29-35, 2012.

RAMACHANDRAN, V. S. Encyclopedia of the Human Brain. vol. 4. New York: Academic Press, Inc., p.188-190, 2002.

REVUELTA-INIESTA, R.; AL-DUJAILI, E. A. Consumption Of Green coffee reduces blood pressure and body composition by Influencing 11ß-HSD1 enzyme activity in healthy individuals: A pilot crossover study using green and black coffee. Biomed Research International, 2014. Available in: <http://downloads.hindawi.com/ journals/bmri/2014/482704.pdf $>$. Access in: August, 17, 2020.

RYAN, L.; HATFIELD, C.; HOFSTETTER, M. Caffeine Reduces Time-Of-Day Effect on Memory Performance in Older Adult. Psychological Science, 13(1):68-71, 2002.

SCHIEBER, A.; SALDANA, M. D. A. Potato peels: A Source of nutritionally and pharmacologically Interesting Compounds - A Review. Global Science Books, 3(2):23$28,2009$.

SIBIRNY, A. A. Biotechnology of yeasts and filamentous fungi. Springer International Publishing, p.1-38, 2017.

SZENTHE, A. Top Coffee Producing Countries. 2019. Available in: $<$ https://www.worldatlas.com/articles/topcoffee-producing-countries.html $>$. Access in: April, 7, 2020.

TEOH, A. L.; HEARD, G.; COX, J. Yeast Ecology of Kombucha Fermentation. International Journal of Food Microbiology, 95(2):119-126, 2004. 